\title{
The Effects of Stereotypes of Criminals on the Judgments of Criminal Acts
}

\author{
Sang-Moon Lee ${ }^{1} \cdot$ Hee-Chan Park ${ }^{2} \cdot$ Hai-Sook Kim $^{1}$ \\ $\left({ }^{1}\right.$ Ajou University, KOREA $\cdot{ }^{2}$ Dongguk University, KOREA) \\ Key words: stereotype, characteristics of the criminal, judgments of criminal acts
}

According to the Study1 of Park \& Kim (2009), Koreans perceived theft as a stereotypic crime for Southeast Asians living in Korea and fraud as a stereotypic crime for Korean. The previous research (Bodenhausen, 1985; Gordon, 1988) demonstrated that the crimes which were consistent with the ethnic stereotypes were sentenced harsher and judged higher in the likelihood of recidivism than the crimes which were inconsistent with the ethnic stereotypes. Previous research has demonstrated that the evaluations of the targets may be varied in terms of the way of the attributions on the targets' behaviors (Kim, 1993). That is, attribution mediated the processes on which the stereotype-consistency of the behavior influenced the judgment. People might attribute the crimes which were consistent with the ethnic stereotypes to internal causes more than the crimes which were inconsistent with the ethnic stereotypes. As a result, they might judge the criminal behaviors harsher.

In the present study, we investigated whether the judgments of criminal acts were affected by whether these acts were consistent with the stereotypes of the ethnic groups. More specifically, we tested the following hypotheses in this experiment.

First, people might attribute the crimes which were consistent with the ethnic stereotypes to internal causes more than the crimes which were inconsistent with the ethnic stereotypes and this tendency might be more evident for males than for females. Second, people might evaluate the judgments of criminal acts (the likelihood of recidivism and the imprisonment length) which were consistent with the ethnic stereotypes harsher than the crimes which were inconsistent with the ethnic stereotypes and this tendency might be more evident for males than for females. Third, the effects of the ethnic stereotypes on the judgments of criminal acts were expected to be mediated by the degree of the attribution to internal causes. This mediation effect might be more evident for males than for females.

\section{METHOD}

Participants. 153 Korean college students (69 males, 84 females) and 111 general citizens ( 84 males, 27 females) participated in the present experiment.

Materials. Attribution measures which examined participants' attribution of criminal behaviors of the targets consisted of 3 items. An example of items is "How much do you think the target's behavior is due to personality?" To examine the judgment regarding the likelihood of recidivism $\&$ the imprisonment length, two items were used. These items included 9-point scales ( $1=$ not at all 9=very much).

Procedure. Participants read one of the six types of scripts which that varied in terms of Crime Type (2: theft vs. fraud) and Ethnic Group (3: South Asian vs. Korean vs. control). After reading a script, participants were asked to indicate the degree to which were attributed the criminal behavior was caused by internal factors (i.e. personality \& stable factors), as well as to make the judgment regarding the likelihood of recidivism and the imprisonment length.

\section{RESULTS and DISCUSSION}

2(Crime Type: theft vs. fraud) x 3(Ethnic Group of the Target: Southeast Asian vs. Korean vs. control) x 2(Gender: male vs. female) ANOVAs were performed. The results of the ANOVAs on the ratings of "personality attribution" demonstrated a marginally significant two-way interaction (Crime Type $\mathrm{x}$ Ethnic Group of the Target; $F(2,252)=2.67$, $p<.07)$ effect. Respondents attributed fraud of Korean $(M=5.60)$ and that in the control condition $(M=5.90)$ more to a personality factor than fraud of South Asian $(M=4.82)$, while no such interaction obtained for theft, $F(2,258)=1.284, p>.10$.
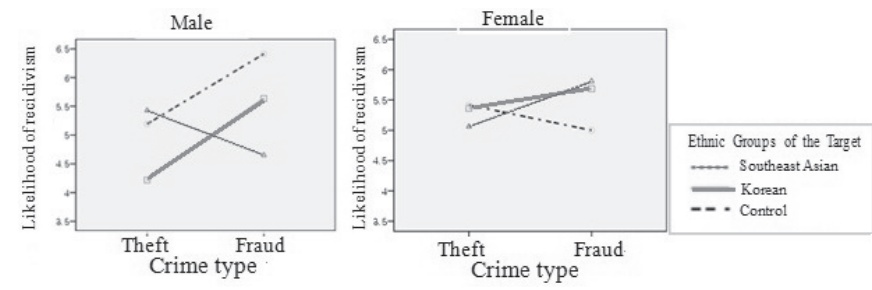

Figure1. Likelihood of recidivism ratings as a function of Crime Type, Ethnic Group of the Target and Gender of the participants

The results of the ANOVAs on the evaluation of "the judgment on likelihood of recidivism" demonstrated a significant three-way interaction (Crime Type $\mathrm{x}$ Ethnic Group of the Target $\mathrm{x}$ Gender; $F(2,252)=4.703, p<.01)$. The results are shown figure1. The simple two way interaction was significant only for male participants. For theft, male respondents evaluated that Southeast Asian $(M=5.43)$ criminal and the criminal in Control condition $(M=5.19)$ would be more likely to repeat the crimes than in the case of Korean $(M=4.22)$ criminal , $F(2,147)=3.008, p<.05$, while for fraud they evaluated that Korean $(M=5.64)$ criminal and criminal in Control condition $(M=6.41)$ would be more likely to repeat the crimes than Southeast Asian $(M=4.65)$ criminal $, F(2,147)=5.439, p<.01$, as expected.

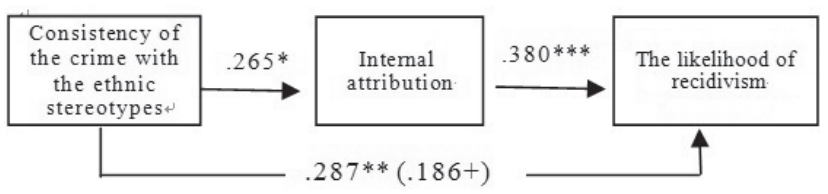

Figure2. Internal attribution as a mediator of the effect of consistency of the crime with the ethnic stereotypes on the judgments of likelihood of recidivism $* * * p<.001, * * p<.01, * p<.05,+p<.06$

To examine whether the effect of the ethnic stereotype consistency of the crime on the judgments of the likelihood of recidivism was mediated by internal attribution, we performed a series of regression analyses following the procedure advocated by Baron and Kenny (1986). Figure2 displays the result. As predicted, the results indicated that the significant link between consistency of the crime with the ethnic stereotypes and the judgments of likelihood of recidivism $(\beta=$. 287, $p<.01)$ disappeared and became nonsignificant when internal attribution was entered as a mediator $(\beta=.186, p<.06$, Sobel' test $Z=2.17, p<.05)$. In other words, the effect of the stereotype consistency of the crime of the judgments of the likelihood of recidivism was accounted for in terms of the effect of internal attribution.

In sum, the results of this study demonstrated that stereotypes of criminals could influence the judgments of criminal acts.

\section{REFERENCES}

Bodenhusen, G.V., \& Wyer, R.S. (1985). Effects of stereotypes on decision making and information-Processing Strategies. Journal of Personality and social Psychology, 48,267-282. 